Revista de Filología Románica

ISSN: 0212-999X

http://dx.doi.org/10.5209/RFRM.58155

\title{
Alonso Zamora Vicente y el folklore
}

Juan Rodríguez Pastor ${ }^{1}$

Recibido: 18 de marzo de 2017 / Aceptado: 4 de octubre de 2017

Resumen. Don Alonso fue un buen folklorista, aunque apenas usó esta palabra. Para temas de folklore, su biblioteca es excelente. Además, en sus trabajos de investigación, recogió abundantes materiales de tradición oral, especialmente en El habla de Mérida. Finalmente, en su obra literaria, vertió numerosos materiales folklóricos: dichos, refranes, adivinanzas, cuentos... Aquí se da cuenta de todo ello. Palabras clave: Alonso Zamora Vicente; folklore español; El habla de Mérida y sus cercanías.

\section{[en] About Alonso Zamora Vicente and Folklore}

\begin{abstract}
This article studies the close relationship between Alonso Zamora Vicente and Folklore. Although he rarely used the term 'folklore', Alonso Zamora Vicente collected many data from the oral tradition and had an excellent library on the topic. He used the evidence of this tradition, including riddles, idioms, and tales, and used it in his research work, such as El habla de Mérida, and in his literary books.
\end{abstract}

Keywords: Alonso Zamora Vicente; Spanish Folklore; El habla de Mérida y sus cercanías.

Sumario: 1. Introducción; 2. Don Alonso, bibliófilo; 3. Don Alonso, recopilador de folklore en sus trabajos dialectológicos; 4. Don Alonso, trasmisor de folklore en su obra literaria; 4.1. Expresiones populares; 4.2. Refranes; 4.3. Creencias y supersticiones populares; 4.4. Tradiciones y costumbres populares; 4.5. Canciones populares, romances...; 4.6. Juegos infantiles; 4.7. Acertijos; 4.8. Chistes; 4.9. Cuentos; 5. Referencias bibliográficas.

Cómo citar: Rodríguez Pastor, J. (2017). Alonso Zamora Vicente y el folklore, en Revista de Filología Románica 34. Núm. especial, 61-71.

\section{Introducción}

Don Alonso fue un buen folklorista; fue una persona que recibió, asimiló, recopiló y transmitió muchos conocimientos de tradición oral ${ }^{2}$. Como investigador, recopiló mucho folklore, especialmente en su tesis doctoral sobre El habla de Mérida y sus cercanías (1943). Contó, además, en su excelente biblioteca, con centenares de

1 IES Benazaire, Herrera del Duque (Badajoz)

Email: jrpastor01@gmail.com

2 No han faltado acercamientos a esta relación de don Alonso con lo popular; por ejemplo, los trabajos de Jesús Sánchez Lobato (1988), Miguel Á. Rebollo (2003) o Leonardo Romero Tobar (2003). 
monografías dedicadas a esta materia. Como escritor, una parte importante de su obra literaria, especialmente la novela Vegas bajas (1987), se sustenta sobre el saber popular que van desgranando los protagonistas en sus largos parlamentos. Por esta razón, en la docena de obras (tanto de investigación como literarias) que hemos revisado para este trabajo, hemos encontrado casi un millar de referencias a los más diversos materiales del folklore: creencias, refranes, canciones, cuentos, juegos, tradiciones, etc. No olvidemos que una de las tareas del Centro de Estudios Históricos fue el estudio del folklore; y que, además, don Alonso se interesó por los materiales de la cultura popular presentes en los textos clásicos de la literatura. Sin embargo, don Alonso apenas usó la palabra folklore; prefirió utilizar etnografía, cultura popular, saber popular, tradición popular, sabiduría popular... Para explicar esta aparente incongruencia y corroborar nuestra afirmación de que don Alonso fue un buen folklorista, hemos analizado tres aspectos de su vida y de su obra: sus facetas de bibliófilo, de recopilador y de transmisor de folklore.

\section{Don Alonso, bibliófilo}

Para temas de folklore, la Biblioteca de don Alonso es excelente ${ }^{3}$. Él mismo, en Sin levantar cabeza, confirma este hecho (1977:133-134): "Yo me he dedicado estos años algo pasables a hacerme con una biblioteca de curiosidades etnográficas y folklóricas" ". Si nos centramos, por ejemplo, en ciertos temas populares, nos sorprende ver que en su Biblioteca andan casi cuatrocientos títulos referidos a los cuentos, con colecciones de cuentos leoneses, aragoneses, gallegos, madrileños, extremeños, cubanos, argentinos, portorriqueños, mejicanos, portugueses, rusos, árabes...; y, por supuesto los cuentos asturianos de doña M. ${ }^{a}$ Josefa Canellada ${ }^{5}$.

Don Alonso también reseñó algunos libros de folklore ${ }^{6}$; y además, algunos de sus relatos llevan títulos relacionados con el folklore: rimas infantiles ("Cinco lobitos"); tradiciones ("Pregones. Primavera en la calle", "Aleluyas"); romances ("Los romances siempre", "En el fondo del mar"); refranes ("Todo tiempo pasado", "Quien quita la ocasión...", "Los duelos, con pan son menos"); creencias ("Infusiones", "Un vidente", "Una vela a Santa Polonia"); villancicos ("A esta puerta hemos llegado..."), etc. Dos obras de su Biblioteca subrayan especialmente el interés que sintió por el folklore: los "Consejos para los que recolectan canciones folklóricas" de S. Eskin (1955) y el Manual-guía para el recolector de Jacovella (1951).

Supongo que, a más de un lector, se le planteará esta duda: si don Alonso estuvo tan relacionado con el folklore, ¿por qué apenas usó esa palabra? Pues ahí va nuestra opinión. La palabra folklore nunca ha tenido buena prensa. La extensión de la

3 Biblioteca depositada en la Fundación Biblioteca Alonso Zamora Vicente, en la denominada Casa del Mono (Cáceres).

4 En su biblioteca encontramos títulos referidos a manuales o a diversas partes de España y de Hispanoamérica como: L. Hoyos Sáinz y N. de Hoyos Sancho (1947), R. Steele Boggs (1949), S. G. Armistead y J. H. Silverman (1965), P. Geiger y R. Weiss (1950), F. Bouza-Brey (1982), E. Peña Hernández (1968) o J. Á. Tió (1979).

5 Estos libros, quizá, serían más utilizados por doña M. ${ }^{\text {a }}$ Josefa Canellada, quien sí publicó abundantes materiales sobre folklore. Véanse títulos de esta autora en 5. Referencias bibliográficas.

6 Como el de L. de Hoyos Sáinz y N. de Hoyos Sancho (1947) y los del profesor norteamericano A. M. Espinosa (1947 y 1953). 
voz inglesa folklore encontró una gran oposición en España y en otras naciones. Y aún se mantienen secuelas de aquellas discusiones. Hace años se discutía sobre si denominarlo folklore o folklor; después, si escribir folklore o folclore. Por otro lado, se escribe con mayúscula, cuando nos referimos a la disciplina; pero, se escribe con minúscula, si nos referimos a los materiales que estudia. Y, además, hoy, aunque el Diccionario de la Academia prefiere folclore, a algunos folkloristas nos gusta seguir escribiéndolo con $\mathrm{k}$. ¡Qué le vamos a hacer!

En España, como tal disciplina y con el nombre de Folklore, aparece en 1881, por iniciativa de don Antonio Machado y Álvarez. Antes, a principios del siglo XIX, había surgido la Etnografía, como una rama de la Geografía e Historia encargada de describir los pueblos primitivos, lejanos al mundo occidental. Quizá por eso, el Folklore se reservó al estudio de la cultura popular que se da en las capas bajas del mundo "civilizado". En una de las obras de la Biblioteca de don Alonso que he destacado, Manual-guía para el recolector, vemos claramente el problema:

Conviene hacer notar que la mayor parte de los etnógrafos y folkloristas del área anglosajona llaman 'Folklore' a toda la cultura oral (poesías, cuentos, leyendas, etc.), y solo a ella, dondequiera que se encuentra, en comunidades no civilizadas o en el substrato de las sociedades civilizadas. Para los demás folkloristas del mundo, en cambio, el Folklore estudia toda la cultura del substrato (civilizado), y la Etnografía, toda la cultura de los grupos no civilizados. Esta es la posición adoptada en la Argentina (Jacovella 1951:2).

Hoy, sin embargo, tienden a equipararse ambas ciencias. $Y$ en muchos casos aparecen los dos términos juntos: "Etnografía y Folklore de..."; pero, en fin, por estos problemas que ha tenido la palabra folklore, sería comprensible que don Alonso apenas la utilizara, aunque, al final, reconocía haberle prestado "especial atención"?

\section{Don Alonso, recopilador de folklore en sus trabajos dialectológicos}

En sus trabajos dialectológicos, don Alonso recogió materiales de tradición oral. En su libro Léxico rural asturiano (1953), hallamos pocos materiales folklóricos, apenas una decena. Más referencias encontramos, sin embargo, en su trabajo "Notas para el estudio del habla albaceteña" (1943); y, sobre todo, es en El habla de Méri$d a$ (1943) donde don Alonso nos dejó un buen libro de folklore. Allí, además de las descripciones etnográficas del carboneo y del corcho, hay más de un centenar de referencias a materiales folklóricos, y lo más importante, referencias de calidad. Por ejemplo, recoge más de veinte juegos, con explicaciones que unas veces se complementan con dibujos, caso del calajanso, y otras ocupan más de dos páginas, como periquillo el aguador. Incluso dedica el autor una lámina a las denominaciones del juego infantil de la toña. Pero, sin duda, los materiales folklóricos que destacan en El habla de Mérida son los referidos a los dictados tópicos, a los dichos referidos a

En Compostela, años atrás (1993:43), afirma: "Pero yo me atrevo a pensar [...] que en aquel curso de verano de 1945, el oficialmente desdeñado espíritu de la Institución Libre de Enseñanza y de sus consecuencias volvió a pasearse por una Universidad española. El interés por lo popular, el folklore, al que dimos especial atención en nuestras lecciones...". 
los pueblos y a sus habitantes (ajumao, barrigones, bellotero, galapaguero...). Más de cuarenta dictados recoge don Alonso, dedicándoles, incluso, una lámina.

\section{Don Alonso, trasmisor de folklore en su obra literaria}

Don Alonso, en su obra literaria, vertió numerosos materiales de saber popular asimilados durante su vida. Como él mismo reconoce en el prólogo de Hablan de la feria...: "Todo cuanto viene en estas páginas [...] se lo he oído a alguien" (1995:6). Los protagonistas de sus obras hablan como la gente de la calle; por eso, sus parlamentos están salpicados de referencias y de materiales folklóricos: dichos, refranes, cuentos, aleluyas, gastronomía, medicina popular...

Para intentar corroborarlo, hemos releído una decena de libros y algunos relatos de don Alonso. En Un balcón a la plaza (1965) solo registramos siete referencias a materiales folklóricos; en Sin levantar cabeza (1977) y en ;Estos pobres diablos! (1999), localizamos treinta y cinco; en Tute de difuntos (1982), cuarenta; en Mesa, sobremesa (1980) y en El mundo puede ser nuestro (1976), setenta; en A traque barraque (1972), ochenta y cinco; en Hablan de la feria ... (1995), más de cien; y en Vegas bajas (1987), el libro más extenso, encontramos más de trescientas referencias. No es necesario aclarar que algunos ejemplos se repiten en un mismo libro y en los distintos libros. Una expresión como "QQue si quieres arroz, Catalina!", se localiza en A traque barraque (1972:273), en Mesa, sobremesa (1980:119), en Vegas bajas (1987:69 y 517) y en Hablan de la feria... (1995:98, 127 y 214). Tampoco hay que tomar los números al pie de la letra. Las referencias de algunos apartados podríamos incluirlas perfectamente en otro $\mathrm{u}$ otros, porque los materiales de la tradición oral no siempre se dejan etiquetar. Veamos algunos ejemplos.

\subsection{Expresiones populares}

Las expresiones populares conforman, sin duda, los materiales de tradición oral más abundantes en la obra literaria de don Alonso. En Vegas bajas superan el centenar. Son expresiones del tipo: "No jodas la marrana"; "A mí, plim"; "en menos que se persigna un cura loco"; "de chipendi lerendi"; "qué gentecica lleva la Virgen", etc. Y no faltan ejemplos de expresiones populares rimadas: "a otra cosa, mariposa"; "Chupa del frasco, Carrasco"; "no te enrolles, Charles Boyer", etc. A veces, don Alonso enlaza dos o más expresiones populares: "y venga y dale, y duro que te pego"; "y que si patatín y que si patatán, y que si fue y que si vino"; "Sí, sí, al freír será el reír, o fíate de la Virgen y no corras, y métele un dedo en la boca y ya verás"; "cada quien es cada quien y a joderse tocan"; etc.

\subsection{Refranes}

Cercanos a las expresiones populares están los refranes, casi un centenar, que hemos encontrado en su obra. Vegas bajas, con treinta y Mesa, sobremesa, con veinte, son las obras con mayor número de referencias. Los refranes fueron muy del gusto de don Alonso. Los utilizó incluso para el título de algunos relatos, como, por ejemplo, 
en "Quien quita la ocasión..." (1991) $)^{8}$ "Los duelos, con pan son menos" (1994), etc. A los refranes dedicó también don Alonso el prólogo del Refranero español: refranes, clasificación, significación y uso (2001), y, además, unas hermosas palabras en 1996, en la inauguración del Primer Congreso Internacional de Paremiología celebrado en la Universidad Complutense de Madrid (1997). Por supuesto, don Alonso manejó los refranes con soltura, con la habilidad de quien los utiliza habitualmente: "Carne en calceta, para quien la meta" (1972:75); "Llevaba su razón el chaval al recordar el refrán: A la mierda, abanico, se acabó el verano" (1995:231); etc. Por eso, en muchas ocasiones juega con ellos, dejándolos a medias, con unos puntos suspensivos o un etcétera: "No hay mal que etcétera", "Marzo ventoso...", "Quien con niños se acuesta...", "El buey suelto...", "genio y figura...", "los duelos con pan ya se sabe ...", "donde quiera que fueres, pues eso", etc.

En otras ocasiones, modifica los refranes, generalmente con un propósito humorístico: "Ya lo dice el refrán. A Carnero Regalado, frénale el diente. Oiga, no sea panoli, a ver si usted se cree que yo no sé cómo es el refrán de verdad. ¿Quiere que le enseñe unos cuantos? Ah, pues entonces" (1972:160); "Las cosas a su debido tiempo, ¿o no? Y las uvas en habiendo" (1980: 95); "Bueno, ya sabe usted, el muerto al joyu, y el cura al bollu, que dicen en mi tierra" (1980:152), etc.

A veces don Alonso engarza dos o tres refranes: "como debía ser llamar al pan, pan, y al vino, vino, y donde las dan las toman y al que no le guste que se friegue y ya está" (1976:159), etc. Y no faltan ocasiones en que creemos que los refranes son inventados, quizá por el propio don Alonso o por alguna persona de su entorno: "ya sabe usted el refrán: El cabrito, o se lo comen o se hace cabrón" (1976:152). Por inventar, hasta se inventa o toma de alguien a quien se lo escucha, el verbo refranear: "y aún tenía fuerzas para refranear" (1987:38).

\subsection{Creencias y supersticiones populares}

El mundo de las creencias y supersticiones populares también fue muy del agrado de don Alonso. Hemos encontrado unas 130 referencias, algunas extensas. Además, estas aparecen bastante repartidas, de forma que en casi todas sus obras podemos espigar media docena. La palma, sin duda, se la llevan Hablan de la feria ... (1995), con más de veinte testimonios, y, por supuesto, Vegas bajas (1987), con casi sesenta. En esta última obra hay todo un capítulo (1987:150-161) dedicado a las plantas medicinales, un precioso tratado de farmacopea popular, con las propiedades de hierbas como ajenuz, alfóncigo, azufaifas, cirigüeña, culantrillo, escaramujo, matalahúva, ruda, salicaria, yerbaluisa... También se localizan en la obra de Alonso Zamora Vicente creencias y supersticiones populares muy diversas: piedras de rayo (1965:47), mal de ojo (1972:267; 1995:86; 1987:157), amuletos (1976:126; 1987:159-161, 175 y 580), fantasmas (1980:117), enfermedades (1980:117), mala suerte (1987:97), exvotos $(1987: 381 ; 1995: 97)$, etc. Tampoco faltan noticias de personajes que, presuntamente, tienen poderes curativos y/o adivinatorios: curanderos, adivinos, médiums, pitonisas, echadoras de cartas, saludadores... Y no se olvida don Alonso de los que denomina "santos milagreros", especialmente san Antonio: "Y a

$8 \quad$ Publicado también en Hablan de la feria ... (1995:107-114). 
San Antoñico, con eso de que proporciona novios y devuelve lo perdido" (1987: 75); pero también a santa Polonia, san Expedito, santa Rita de Casia...

No faltan inclusiones de conjuros y ensalmos: "Para el garrotillo, por ejemplo, yo recitaba uno muy eficaz: Santo patrón celestial / que de las gargantas cuidas, / no fastidies y vigila / esta tos tan funeral" (1995:174), y de malos augurios: "La gente sigue pensando que cuando un perro ladra así, aullando, gañido va, gañido viene, es que la va a diñar alguien" (1995:85).

\subsection{Tradiciones y costumbres populares}

Como es lógico, abundan las citas a tradiciones y costumbres populares, unas 75, casi la mitad en Vegas bajas: los ciegos que vendían sus romances, los pregones, las aleluyas, la matanza, el magosto, el ramo de los quintos, las cencerradas...; fiestas como las de moros y cristianos, el carnaval, los quintos, el achicharramiento del judas, la puja de las andas, el andar descalzo sobre las brasas, las piñatas, la Navidad (con sus nacimientos, Misa del Gallo, rondallas y villancicos, aguinaldo...), la Semana Santa (con sus torrijas, la prohibición de cantar...), la noche sanjuanera, el Corpus de Camuñas, el toro enmaromado en Benavente, las mayas en Peñalbilla...

\subsection{Canciones populares, romances...}

No abundan en la obra literaria de don Alonso referencias a canciones y romances populares $^{9}$. Apenas podemos señalar una treintena, la mayoría en Vegas bajas. Y son estas, en general, muy breves, limitándose a señalar el primer o los primeros versos:

oigo hasta la voz de mi madre tarareando alguna cancioncilla de la iglesia, o de ronda, que mi madre cantaba mientras cosía, la oigo aún runrunear al mojar el hilo para enhebrar la aguja, y, puntada tras puntada, "echa los surcos derechos a mi ventana, labrador de mi padre serás mañana”, o cualquier cosa sí (1976:144).

y comenzaron a echarse al coleto en la cantina copas de chinchón, cantando "El vino que vende Asunción”, "Los cuatro muleros” y “Asturies, patrie querida” (1987:191); etc.

No faltan en su creación las canciones infantiles de los corros de niñas: "En fin, que no hubo llaves. ¿Está claro? Estarán en el fondo del mar, es inútil perseguirlas" (1972:112); "Todo lo que se canta se ha aprendido de alguien, ¿no? Ahora suele ser del transistor, o de la tele, pero antes se aprendía en la calle, como Mambru" (1987:109); etc.

Hay que hacer una mención a las canciones de la guerra: "canturreaba canciones de la guerra, Si me quieres escribir ya sabes mi paradero" (1976:189); "Por la calle pasaban soldados borrachos, Con el quinto quinto quinto, con el quinto regimiento,

9 Por supuesto también hay recuerdos de canciones modernas, popularizadas por la radio (como el tango de Carlos Gardel: "una faca albaceteña / se la sepulté en el pecho" (1955:36; y 1972:205) o la canción de Imperio Argentina: "por donde quiera que voy, qué mala estrella me guía..." (1987:256); pero, estas canciones no entran en nuestro análisis. 
Ay, chiviri, chiviri, chiviri..., diciendo obscenidades medio entendidas" (1987:489); "Aún le quedó tiempo para avivar la fogata con los himnos de la guerra, A las barricadas, a las barricadas, Con el quinto, quinto, con el quinto regimiento..." (1987:601); etc.

A estas referencias, podemos añadir otras quince referidas a villancicos, la mitad de ellos en Vegas bajas: "Las pandillas de zagalones pasan sacudiendo violentos los panderos, agitando cascabeles. Mira cómo beben / los peces en el río" (1987:469); "Se ve luz en todas las ventanas del pueblo, y se oyen cantos, gritos, bullicio de panderos y zambombas: Ya viene la vieja / con el aguinaldo, / le parece mucho, / le viene quitando... / Pampanitos verdes, / hojas de limón..." (1987:483); etc.

\subsection{Juegos infantiles}

Hemos localizado veintitrés testimonios de juegos, la mitad de ellos en $A$ traque barraque (1972). Muchos serían jugados por don Alonso, porque en la "Carta-prólogo" que escribió al libro de Manuel Casado (2002:10), afirma:

Yo he sido gran jugador del burro. Mi variante era entre varios chicos, ya mayores, de pie. Se le daba al que se quedaba una palmada más o menos agresiva en la palma de su mano, que asomaba por debajo del brazo opuesto, y tenía que adivinar quién le había dado, para cambiar de lugar.

Emparentadas con los juegos están las rimas infantiles que se utilizan para entretener a los niños pequeños. Don Alonso apenas hace referencia a este campo del folklore; pero, sí hay una rima infantil, la de "los cinco lobitos", que utiliza, incluso, en el título de algunos de sus relatos.

\subsection{Adivinanzas}

Sabemos que el tema de las adivinanzas le interesaba a don Alonso, porque en su Biblioteca hay al menos cinco monografías sobre adivinanzas portorriqueñas, colombianas, argentinas, cubanas...; sin embargo, solo hemos encontrado cuatro citas a ese tema en los textos analizados; las mejores son las que dedica a los acertijos de adultos, las "picarescas", aquellas que presentan un texto, generalmente obsceno, pero cuya solución final no puede ser más "inocente". Don Alonso recoge dos de estas en Mesa, sobremesa (1980:158):

aquí sí que vienen al pelo las adivinanzas de mi tierra, la mujer coge el juguete, lo que cuelga queda abajo y en su agujero lo mete, con poco o mucho trabajo, toda esa jarca se empezaría a escandalizar si me oyera, tal por tal y por cual y sacaría a relucir su educación y su apellido, sobre todo su educación, no faltaba más, pues, gilipollas, eso quiere decir el pendiente, el-pen-dien-te-el-pen-dien-te, pues, entonces, ah, mal pensados, coño, $[\ldots]$ te extiendo y abro, no cabe duda, y te hundo una cuarta de carne dura, habría que oírles, je je je, pues es el calcetín, desgraciados, el-cal-ce-tín. 


\subsection{Chistes}

Podemos señalar ocho referencias a chistes, principalmente verdes: "A veces a veces, según la altura del año, alguno se escurre con un chistecito algo subidillo de color, pero sin mayor importancia" (1972:176); pero, como es habitual, no suele trascribir los chistes completos; se limita a hacer una breve alusión, dando por sentado que sus lectores los conocerían. Y, seguramente, en su momento, muchos lectores entenderían la alusión; pero, hoy, tendríamos que revisar la documentación para descifrar el significado de algunas referencias: "El chistecito a base de Calderón es de primero de bachiller, es decir, es... No me haga decir lo que es" (1976:63) 10; “¡Miren, miren, Las Matas! Primero Las Rozas y después Las Matas. Es un chiste muy gracioso, de antes de la guerra" (1981:565)"11. "Eso sí, nos sabíamos de carrerilla los chistes contra el Botas" $(1987: 133)^{12}$; etc.

\subsection{Cuentos}

Y terminaremos este breve repaso a la obra literaria de don Alonso, bajo el prisma del folklore, con un tema que nos gusta mucho, el de los cuentos populares. De ellos podemos señalar una docena de referencias, comenzando por la típica de "el tiempo de Maricastaña" (1972:98) o la de los "cuentos de hadas" (1995:137), los "cuentos verdes" (1982:86) ... Además, como ya hemos visto, don Alonso se limita, a veces, a dejarnos una alusión al cuento, sin desarrollarlo. Eso es lo que hace con este falso cuento, de los de nunca acabar: "y, cuando desperté, mi madre estaba a mi lado, murmurando: Este era un rey que tenía tres hijas, las metió en tres botijas... Nunca más he vuelto a contar esa historieta" $(1987: 136)^{13}$. También deja inconclusas las siguientes referencias a otros cuentos: "Pues mire, que se lo cuenten en su casa, que también deben de saberlo, no voy a ser yo solito el que mosconee siempre con la historia del español piojoso, ¿no?” (1977:79); "Al freír será el reír”"14; "Coño, coño, coño..."15; y "¡Quién te ha visto y quién te ve, ciruelo!"16.

Para terminar, intentaremos explicar estos últimos cuentos. El del español piojoso, creemos que es una versión del cuento "Tijeretas han de ser", que se utiliza para indicar la tozudez de una persona ${ }^{17}$. "Al freír será el reír" es la frase en que se resu-

10 Quizá se refiera al conocido chiste del inspector que visita una escuela y empieza a preguntar a los alumnos quién escribió el Quijote. Como ninguno responde correctamente, el inspector, contrariado, exclama: “iAy, pobre Calderón de la Barca, cómo te han olvidado!”.

11 Se refiere a que, al salir de Madrid, los viajeros encontraban Las Rozas y después Las Matas.

12 Se refiere a los chistes contra don Niceto Alcalá Zamora, a quien la prensa satírica solía denominar despectivamente El Botas.

13 Mi madre me lo contaba así: "Esto era un rey / que tenía tres hijas, / las metió en tres botijas, / las tapó con pez, / ¿quieres que te le cuente otra vez?” (Rodríguez Pastor 2002:57).

14 “Al freír será el reír. Ya dará la vuelta la tortilla” (1980:107); “Sí, sí, al freír será el reír, o fíate de la Virgen y no corras, y métele un dedo en la boca y ya verás...” (1987:164).

15 “Coño, coño, coño...” (1987:114); “y aún tenía fuerzas para refranear, coño, coño, coño, y qué gentecica lleva la Virgen" (1987:38).

16 La expresión puede consultarse en los siguientes textos: 1972:179; 1980:73; 1987:147 y 509; y $1995: 137$.

17 Había una mujer que se empeñaba en llamar tijeretas a los zarcillos de la vid, por lo que el marido, enfadado, la tiró al río. La mujer, mientras se hundía, sacaba dos dedos de la mano, juntándolos y separándolos, simbolizando las tijeretas. El cuento lo recoge el Arcipreste de Talavera, en el Corbacho. 
me otro cuentecillo, el de un calderero que vendió una sartén que estaba rota; $y$, a su vez, el comprador le pagó con una moneda falsa. Ninguno se dio cuenta del engaño; y, como el comprador se reía, le dijo el calderero: "Al freír será el reír". A lo que le contestó el otro: "Y al contar será el llorar"18. La expresión "coño, coño, coño", que indica sorpresa y comprensión, resume un cuento, aunque desconocemos qué versión conocería don Alonso. En mi pueblo, mi suegro me contó hace años (2001:215) la de un hombre que iba a misa, mojaba en la pila de agua bendita y siempre decía: “¡Coño, coño, coño...!”. Así que, un día, el cura le preguntó por qué todos los días decía “coño, coño, coño". Y el hombre le dice:

- Porque, mire usté, señor cura: mi mujer, blanca; y yo, blanco; y tengo una hija negra. Dice el cura:

-¡Ay, coño, coño, coño...!

Y, finalmente, la frase "¡Quién te ha visto y quién te ve, ciruelo!", resume otro cuentecillo popular muy extendido. Esta es una versión extremeña (2001: 318):

Pues es que había un hombre que tenía en su güerto un ciruelo mu grande que no había echao nunca una ciruela, ni una; y ya se secó. Y entonces vino un cura nuevo y le dijo, dice:

-¡Dies, qué ciruelo más bueno tiene usté ahí!

Dice:

-Pos qué lástima, se ha secao.

-Áber, pos, si quiere usté -dice-, lo que podemos hacer es un santo de él.

Bueno, pues nada, se le llevaron al carpintero y preparó un santo. Y luego claro, el amo del güerto fue y le vio allí ¡y tú verás si conocía el ciruelo!, y dice:

-Quien te conoció ciruelo...,

los milagros que tú hagas

que me los cuelguen a mí

de los güevos.

\section{Referencias bibliográficas}

Armistead, Samuel G. y Joseph H. Silverman (1965): Folklore in Latin America. Los Ángeles: Universidad de California.

Boggs, Ralph Steele (1949): "Folklore classification". Southern Folklore Quarterly 13:161-226.

Bouza-Brey, Fermín (1982): Etnografía y folklore de Galicia. Vigo: Xerais.

Canellada M. ${ }^{a}$ Josefa (1978): Cuentos populares asturianos. Gijón: Ayalga ediciones.

Canellada M. Josefa (1983): Leyendas, cuentos y tradiciones (Folklore de Asturias). Gijón: Ayalga ediciones.

18 Lo recogen J. M. Sbarbi y Osuna (1943) y J. M. ${ }^{\text {a }}$ Iribarren (1955). 
Canellada M. ${ }^{a}$ Josefa y Berta Pallares (1997): Refranes: 700 refranes españoles con sus correspondientes daneses. Copenhagen: Museum Tusculamum Press.

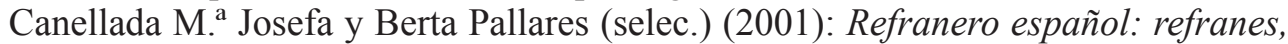
clasificación, significación y uso. Madrid: Castalia.

Casado Velarde, Manuel (2002): El léxico diferencial de Don Benito. Don Benito: Fondo editorial del Ayuntamiento.

Eskin, Sam (1955): “Consejos para los que recolectan canciones folklóricas”. Folklore Americas 15 (2):7-14.

Geiger, Paul y Rich Weiss (1950): Atlas de Folklore Suisse. Basilea: Schwizerische Gesellschaft Für Volkskunde.

Hoyos Sáinz, Luis de y Nieves de Hoyos Sancho (1947): Manual de folklore. La vida popular tradicional de España. Madrid: Revista de Occidente.

Iribarren, José M. (1955): El porqué de los dichos. Madrid: Aguilar.

Jacovella, Bruno (1951). Manual-guía para el recolector. Encuesta folklórica general del Magisterio. La Plata: Instituto de la Tradición, Ministerio de Educación de la Provincia de Buenos Aires.

Peña Hernández, Enrique (1968): Folklore de Nicaragua. Masaya: Unión.

Rebollo Torío, Miguel Ángel (2003): "Recursos lingüísticos cultos y populares en Cuentos con gusano dentro", in C. Alemany Bay et al (eds.), Con Alonso Zamora Vicente: (Actas del Congreso Internacional "La Lengua, la Academia, lo Popular, los Clásicos, los Contemporáneos ...”), vol. I, pp. 353-365. Alicante: Universidad de Alicante.

Rodríguez Pastor, Juan (2001): Cuentos extremeños obscenos y anticlericales. Badajoz: Diputación.

Rodríguez Pastor, Juan (2002): Cuentos extremeños de costumbres. Badajoz: Diputación.

Romero Tobar, Leonardo (2003): “Alonso Zamora Vicente y la tradición popular de nuestra literatura", in C. Alemany Bay et al (eds.), Con Alonso Zamora Vicente: (Actas del Congreso Internacional "la Lengua, la Academia, lo Popular, los Clásicos, los Contemporáneos ...”), vol I, pp. 215-222. Alicante: Universidad de Alicante.

Romero Tobar, Leonardo (2013): Maestros amigos. Santander: Universidad de Cantabria.

Sánchez Lobato, Jesús (1988): "Aspectos lingüísticos en A traque, barraque”, in P. Peira et alii (coords.), Homenaje a Alonso Zamora Vicente, vol I, pp. 491-500. Madrid: Castalia.

Sbarbi y Osuna, José Ma (1943): Gran Diccionario de Refranes. Buenos Aires: J. Gil.

Tió Nazario, Juan Ángel (1979): Esencia del folklore portorriqueño. San Juan de Puerto Rico: [s. n.].

Zamora Vicente, Alonso (1943): El habla de Mérida y sus cercanías. Madrid: Anejo XXIX de la Revista de Filología Española.

Zamora Vicente, Alonso (1943): "Notas para el estudio del habla albaceteña". Revista de Filología Española 27:233-265.

Zamora Vicente, Alonso (1947): "Luis de Hoyos Sáinz y Nieves de Hoyos Sancho, Manual de folklore. La vida popular tradicional de España, Madrid, Revista de Occidente, 1947”. El Faro (14/09/1947). Vigo. 
Zamora Vicente, Alonso (1947): “Aurelio M. Espinosa, Cuentos populares españoles recogidos de la tradición oral de España, Madrid, CSIC, 1946”. Ínsula 16:5.

Zamora Vicente, Alonso (1951): "Pregones. Primavera en la calle". La Nación (18/03/1951). Buenos Aires.

Zamora Vicente, Alonso (1953): Léxico rural asturiano. Palabras y cosas de Libardón (Colunga) y léxico de la cestería popular. Granada: Universidad de Granada, Colección Filológica, vol. VI.

Zamora Vicente, Alonso (1955): “Aurelio M. Espinosa, Romancero de Nuevo Méjico, Madrid: CSIC, 1953”. Insula, 113:7.

Zamora Vicente, Alonso (1997): Léxico rural asturiano. Palabras y cosas de Libardón (Colunga) y léxico de la cestería popular (edición facsimilar). Oviedo: Academia de la Llingua Asturiana.

Zamora Vicente, Alonso (1953): “Aleluyas”. La Nación (05/04/1953). Buenos Aires.

Zamora Vicente, Alonso (1953): "Música en la calle”. Azul 1. Montevideo.

Zamora Vicente, Alonso (1954): “Los romances siempre”. La Nación (24/01/1954). Buenos Aires.

Zamora Vicente, Alonso (1955): Primeras hojas. Madrid: Ínsula.

Zamora Vicente, Alonso (1965): Un balcón a la plaza. Madrid: Alfaguara.

Zamora Vicente, Alonso (1972): A traque barraque. Madrid-Barcelona: Alfaguara.

Zamora Vicente, Alonso (1976): El mundo puede ser nuestro. Madrid: Ediciones del Centro.

Zamora Vicente, Alonso (1977): Sin levantar cabeza. Madrid: Magisterio Español.

Zamora Vicente, Alonso (1980): Mesa, sobremesa. Madrid: Magisterio Español.

Zamora Vicente, Alonso (1981): "Regreso dominguero". Cuadernos Hispanoamericanos 369:551-570. También en Biblioteca Virtual Miguel de Cervantes, www.cervantesvirtual.com/descargaPdf/regreso-dominguero.

Zamora Vicente, Alonso (1982): Tute de difuntos. Santander: La Isla de los Ratones.

Zamora Vicente, Alonso (1985): “Cinco lobitos". Ya (30/06/1985). Madrid.

Zamora Vicente, Alonso (1987): Vegas bajas. Madrid: Espasa-Calpe.

Zamora Vicente, Alonso (1990): "Mis cinco lobitos". Ahorro 245:24-25.

Zamora Vicente, Alonso (1991): “Quien quita la ocasión...”. Ahorro 256:28-29.

Zamora Vicente, Alonso (1992): "Si yo supiese el conjuro". Ahorro 267:22-23.

Zamora Vicente, Alonso (1993): Compostela, años atrás. Santiago de Compostela: Universidad de Santiago de Compostela.

Zamora Vicente, Alonso (1993): “A esta puerta hemos llegado...”. Ahorro 270:1819.

Zamora Vicente, Alonso (1994): "Los duelos, con pan son menos". Ahorro 289:10-11.

Zamora Vicente, Alonso (1995): Hablan de la feria .... Barcelona: Círculo de Lectores.

Zamora Vicente, Alonso (1997): “Acto de inauguración”. Paremia 6:10-12.

Zamora Vicente, Alonso (1999): ¡Estos pobres diablos! Madrid: Biblioteca Antonio de Nebrija.

Zamora Vicente, Alonso (2001): "Prólogo", in M. ${ }^{\mathrm{a}}$ J. Canellada y B. Pallares (selec.), Refranero español: refranes, clasificación, significación y uso. Madrid: Castalia.

Zamora Vicente, Alonso (2002): “Carta-prólogo", in M. Casado Velarde, El léxico diferencial de Don Benito. Don Benito: Fondo editorial del Ayuntamiento. 